\title{
LEI DA FICHA LIMPA: PRINCIPAIS MUDANÇAS E SEU FUNCIONAMENTO
}

Fabíola Soares de Melo, Marcos Vinicius da Silva e Thainá Arcanjo da Costa Silva.

Universidade do Oeste Paulista, Presidente Prudente, SP. E-mail: fabiola.fah.melo@hotmail.com, m.vinis.evil@gmail.com e tatyarcanjo1@gmail.com.

\section{RESUMO}

O objetivo desse estudo foi a compreender o funcionamento da lei complementar n.o 135 de 2010, mais conhecida como "Lei da Ficha Limpa", pois no meio de tantos escândalos envolvendo membros do nosso sistema legislativo e a prática da corrupção (ativa e passiva), tal lei visa coibir os atos criminosos, impedindo a candidatura de indivíduos envolvidos em investigações nos chamados crimes de colarinho branco por até oito anos.

A Lei supracitada é uma das leis que tem maior eficácia e aprovação popular, causando grandes mudanças principalmente no modo de voto (associado em uma escolha consciente e confiança na mesma) e candidatura (candidatar apenas quem não tem histórico negativo).

Palavras-chave: ficha limpa, corrupção, crimes de colarinho branco, eficácia, candidatura.

\section{THE LAW OF THE CLEANING RECORD: MAIN CHANGES AND THEIR OPERATION}

\begin{abstract}
The purpose of this study was to understand the operation of complementary law no. 135 of 2010, better known as "Clean record Law", because in the midst of so many scandals involving members of our legislative system and the practice of corruption (active and passive), this law aims to curb criminal acts, preventing the application of individuals involved in investigations in so-called "white collar crimes" for up to eight years.

The above-mentioned Law is one of the laws that have the most effective and popular approval, causing great changes mainly in voting mode (associated in a conscious choice and trust in it) and candidacy (apply only to those who do not have a negative history).
\end{abstract}

Keywords: Clean record, corruption, white collar crimes, effectiveness and application. 


\section{INTRODUÇÃO}

Desde ao muito se lembrado acerca da história do Brasil, a corrupção é um marco negativo que assombra nossa história, membros do poder legislativo cometem tais crimes em benefício próprio, muitas vezes desviando valores de até mesmo merenda escolar de cidades remotas e pobres.

A Lei Complementar no. 135 de 2010 (Lei da Ficha Limpa) busca dar um basta a essa situação, porem sua efetividade no ordenamento jurídico brasileiro ainda é muito discutido, principalmente quando existem casos no país de situações envolvidas com crimes eleitorais quase diariamente.

O presente artigo visa a compreensão desta lei e sua aplicação, criando um comparativo entre as mudanças ocorridas após sua chegada e como era antes do início da sua vigência, principalmente a influência em futuras eleições, pois esta lei tornou-se necessária para que nosso país supere problemas associados a corrupção envolvendo membros do nosso poder legislativo.

\section{METODOLOGIA}

O presente estudo foi desenvolvido a partir do levantamento biográfico, seguindo o método dialético-dedutivo, com o emprego de pesquisa à legislação, doutrina, jurisprudência e reportagens sobre o assunto.

\section{RESULTADOS}

A chamada Lei da Ficha Limpa (Lei Complementar n. 135 de 2010), foi um projeto de lei foi aprovado pela Câmara dos Deputados, com votação unânime pelo Senado Federal e sancionada pelo presidente Luiz Inácio Lula da Silva em 4 de julho de 2010, sendo um texto infraconstitucional, no qual o seu escopo é a regulamentação referente a elegibilidade.

Segundo explana Alexandre de Moraes:

A elegibilidade nada mais é do que a capacidade eleitoral passiva consistente na possibilidade de o cidadão pleitear determinados mandatos políticos, mediante eleição popular, desde que preenchidos certos requisitos. (MORAES, 2017, p. 245).

Para um candidato ser eleito, é necessário preencher os requisitos regidos pela Constituição Federal no seu Art. 14, §3으, conforme exposto abaixo:

Art. 14. A soberania popular será exercida pelo sufrágio universal e pelo voto direto e secreto, com valor igual para todos, e, nos termos da lei, mediante:

[...]

$\S$ 3으o São condições de elegibilidade, na forma da lei:

I - a nacionalidade brasileira;

II - o pleno exercício dos direitos políticos

III - o alistamento eleitoral;

IV - o domicílio eleitoral na circunscrição;

$\mathrm{V}$ - a filiação partidária;

VI - a idade mínima de:

a) trinta e cinco anos para Presidente e Vice-Presidente da República e Senador;

b) trinta anos para Governador e Vice-Governador de Estado e do Distrito Federal;

c) vinte e um anos para Deputado Federal, Deputado Estadual ou Distrital, Prefeito, Vice-

Prefeito e juiz de paz;

d) dezoito anos para Vereador.

[...]

(BRASIL, 1988).

A Lei da Ficha Limpa nasceu da necessidade de medidas que protegessem o eleitor brasileiro fazendo que todos os indivíduos que se candidatem a cargos legislativos do Brasil, sejam honestos e sem envolvimento em crimes principalmente associados à corrupção, os famosos crimes de colarinho branco, ou seja, temo propósito de tornar inelegível o candidato (por oito 
anos) que tiver em seu histórico renúncias para evitar a cassação de mandato, a cassação ou condenação por condenado por decisão de órgão colegiado (ex. STJ, STF entre outros, não sendo cabível em primeira instância), mesmo com a existência de vias recursais.

Vale salientar que esta lei não proíbe a candidatura, porem após o transito em julgado cabe ao TSE, não permitir a posse por o mesmo ter sido condenado, nos moldes da Lei no. 135 de 2010 (Lei da Ficha Limpa).

Tal lei tem como antecedente e alicerce a Lei das Condições de Inelegibilidade ou Lei Complementar no. 64 de 1990, que teve origem de um projeto de lei de iniciativa popular que reuniu cerca de cerca de 1,6 milhão de assinaturas, com o principal objetivo de aumentar a idoneidade dos candidatos a cargos legislativos.

Outras mudanças são acerca da quantidade anos em que o candidato ficará inelegível, anteriormente inelegível por apenas por 3 anos, passando a ser um prazo de 8 anos.

Para um candidato se tornar inelegível, basta ser pedido por qualquer órgão diante da Justiça Eleitoral, apresentando juntamente com a acusação as provas do crime.

A Lei da Ficha Limpa através de suas mudanças, como já explanado, está sendo aplicada em sua totalidade, podemos observar tal aplicação mesmo sendo duvidosa e dividindo opiniões públicas através de julgados pelo TSE (Tribunal Superior Eleitoral):

RECURSO ELEITORAL. DOAÇÃO ACIMA DO LIMITE. COMPROVAÇÃO. EFEITO AUTÔNOMO EM RELAÇÃO A APLICAÇÃO DA SANÇÃO DE INELEGIBILIDADE PREVISTA NA LC 64/90, ART. 1ㅇ, INCISO ! , ALÍNEA P.APLICAÇÃO DA LEI DA FICHA LIMPA A FATOS OCORRIDOS NASELEIÇÕES DE 2010. RECURSO NÃO CONHECIDO.

1. Restando comprovado nos autos a prática de doação acima do limite e reconhecendo o recorrente tal ilícito, resta prejudicada uma das condições da ação, vez que a sanção de inelegibilidade se constitui em consequência automática.

2. É irrelevante o momento da prática do ilícito, vez que, de acordo com o entendimento pacificado pelo Supremo Tribunal Federal, através da decisão proferida na ADC №. 29, a Lei da Ficha Limpa é aplicável também a fatos praticados antes da sua edição.

3. Recurso não conhecido.(TSE, 2012)

A aplicação no Direito Constitucional desta Lei resulta diretamente na suspensão dos direitos políticos antes exercido por aquele que cometeu o crime político. Importante ressaltar que a restrições dos direitos estão relacionadas a prisão e a condenação de segunda instância. $O$ que muito se confunde, pois acredita-se que basta a prisão. Observa Rodrigo Padilha:

A prisão não gera restrição aos direitos políticos, porém a decisão colegiada condenatória pode restringir direitos políticos passivos, e o trânsito em julgado restringe direitos políticos ativos e passivos. (PADILHA, 2014, s/no.)

Em conformidade com a Constituição e Lei Complementar, para a interpretação não basta somente a leitura desses, como também para a complementação a Súmula 9 do TSE deve ser interpretada em conjunto. Dispõe a Súmula 9:

A suspensão de direitos políticos decorrente de condenação criminal transitada em julgado cessa com o cumprimento ou a extinção da pena, independendo de reabilitação ou de prova de reparação dos danos.(TSE, 1992)

A sociedade coloca a culpa da atual crise econômica enfrentada pelo nosso pais nos problemas provenientes da corrupção por parte dos nossos governantes, pois muitos deram causa aos rombos existentes nos cofres públicos, onde políticos corruptos superfatura em obras da União aliadas as grandes empreiteiras e empresas fantasmas.

A mídia em algumas de suas reportagens cita a Lei da Ficha Limpa quando há novos escândalos envolvendo tais crimes que cada vez ocorrem e mais, fazendo que a sociedade duvide da aplicabilidade desta lei e funcionalidade do nosso poder judiciário. 
A Lei da Ficha Limpa está sendo aplicada, mas o que muitos não compreendem que nossos problemas são recentes, a crise brasileira é resultado de décadas de desvio e crimes políticos que não serão resolvidos completamente em apenas oito anos, mas sim com o afastamento de todos os que já tiveram envolvimento com tais crimes do nosso poder legislativo.

\section{CONCLUSÃO}

A Lei da Ficha Limpa é uma medida necessária para proteger o eleitor brasileiro pois dessa forma só pode ser eleito aos cargos legislativos os candidatos que não tem associados à corrupção, sendo assim, com uma escolha sabia a longo prazo podemos superar os problemas existentes, principalmente associados ao desvio de verbas públicas.

Esta lei tende a cada vez mais se adaptar para que em cada eleição sejam eleitos apenas quem levará o pais a um maior desenvolvimento social e financeiro.

\section{REFERÊNCIAS}

BRASIL. Congresso Nacional. Presidência da República. Lei Complementar n.o 64 de 18 de maio de 1990. Estabelece, de acordo com o art. 14, § 9 da Constituição, casos de inexigibilidade, prazos de cessação e determina outras providências. Planalto. Disponível em:

<http://www.planalto.gov.br/ccivil_03/Leis/LCP/Lcp64.htm>. Acesso em: 08 de ago. de 2018.

BRASIL.Congresso Nacional. Presidência da República. Lei Complementar n. 135 de 04 de junho de 2010. Dispõem acerca de casos de inexigibilidade, prazos de cessação e determina outras providências. Planalto. Disponível em:

<www.planato.gov.br/ccivil_03/Leis/Icp/Lcp135.htm>. Acesso em: 08 de ago. de 2018.

BRASIL. Código Eleitoral. Lei no. 4.747 de 15 de julho de 1965. Institui o Código Eleitoral. Disponível em: <http://www.planalto.gov.br/ccivil_03/LEIS/L4737.htm>. Acesso em: 06 de ago. de 2018.

BRASIL. Constituição (1988). Constituição da República Federativa do Brasil. Brasília: Senado Federal, 1988.

BRASIL. Tribunal Regional Eleitoral do Pará. TRE-PA - RE: 4031 PA, Relator: JOÃO BATISTA VIEIRA DOS ANJOS, Data de Julgamento: 18/12/2012, Data de Publicação: DJE - Diário da Justiça Eletrônico, Tomo 1, Data 08/01/2013, Página 4. Disponível em:

<https://tre-pa.jusbrasil.com.br/jurisprudencia/23139552/recurso-eleitoral-re-4031-pa-trepa>. Acesso em: 07 de ago. de 2018.

BRASIL. Tribunal Superior Eleitoral.DJ de 28, 29 e 30.10.1992. Tribunal Superior Eleitoral. Disponível em:

<http://www.tse.jus.br/legislacao/codigo-eleitoral/sumulas/sumulas-do-tse/sumula-nb0-9>. Acesso em: 08 de ago. de 2018.

LADEIRA, Beatriz Maria do Nascimento. Compreendendo a Lei da Ficha Limpa. Revista Eletrônica EJE n. 4, ano 5, setembro/agosto de 2015. Disponível em: <http://www.tse.jus.br/o-tse/escola-judiciaria-eleitoral/publicacoes/revista-daeje/artigos/revista-eletronica-eje-n.-4-ano-5/digressoes-sobre-as-doacoes-decampanha-oriundasde-pessoas-juridicas>. Acesso em: 30 de jul. de 2018. 
Moraes, Alexandre de. Direito Constitucional. 33a edição. Atlas, 02/2017.

PADILHA, Rodrigo. Direito Constitucional, 4ạ edição. Método, 01/2014. 